\title{
Rafael Bernal, un Escritor Mexicano Escribiendo Desde Filipinas
}

\section{Salvador García}

University of Miami, Florida, US

\section{Resumen}

El presente ensayo ofrece un acercamiento a la obra y pensamiento que el escritor Rafael Bernal desarrolló sobre Filipinas y más precisamente sobre la historia del Océano Pacífico en su conjunto. El trabajo hecho por el también narrador y dramaturgo es el primero de este calibre que se lleva a cabo desde México. Su importancia radica en que Bernal buscaba dar a conocer una historia que, hasta la fecha, es casi desconocida por la mayoría de sus connacionales. Se trata de la historia de conquista con la que nace el pueblo moderno mexicano y que hizo que sus navegantes, soldados y capitanes lograran la conquista de Oriente en el siglo XVI.

Las crónicas del momento describen la gesta de esta manera: fueron los "mexicanos" quienes lograron asentarse en Filipinas y, desde ahí, establecer una ruta comercial que tenía a Manila y Acapulco como los dos ejes de la ecuación marítima. El flujo constante de mercancía hizo que la cultura mexicana se nutriera de las costumbres llegadas de Asia, principalmente del Archipiélago de San Lázaro, logrando una hermandad entre los pueblos que se vio rota y olvidada a partir de que la capitanía de Filipinas pasa a manos de España, cuando México logra su independencia en 1821. 
Para alcanzar este grado de reflexión Bernal gozó con la oportunidad de fungir como diplomático en Filipinas en la década de los sesenta. Durante los cuatro años de su labor en Asia pudo entrar en contacto con diversos intelectuales de Manila, entre ellos Antonio M. Abad, en quien encontró un alma siamesa. En el presente trabajo se demuestra cómo los discursos literarios de ambos escritores explotaron las mismas vetas e incluso se lleva a cabo un ejercicio de literatura comprada donde se concluye que dos narraciones de Bernal están basadas en la novela El Campeón de Abad.

El ensayo se encuentra dividido en dos partes. En la primera se muestra una pequeña biografía de Bernal antes de emprender su viaje a Oriente e igualmente se enumeran sus obras más significativas de la época. En la segunda, el texto presenta el abrevadero intelectual que Bernal halló en Filipinas en donde pudo gestar su gran obra, titulada El gran océano.

\section{Palabras clave}

Biografía, El Campeon, El Gran Océano, Mexico, Rafael Bernal

\section{Abstract}

This paper offers an approach to the historic and literary work developed by the Mexican writer Rafael Bernal about the history of the Philippines, and more precisely about the Pacific Ocean. Bernal, who was also an accomplished narrator and a playwriter, made most of the research on this topic in Mexico. The importance of his work lies in the fact that he was seeking to make public a part Mexican national history, which remains unknown to most of his countrymen even today.

Th chronicles written during those days presented the facts in such an order. First, it was the people from New Spain who were able to settle in the Philippines. After the inaugural trip, the newcomers established a fresh commercial route from America to the archipelago. The cities of Manila and Acapulco were the cores of that maritime way. As it is well known, the 
constant flow of merchandise influenced the Mexican culture, inheriting Asian traditions, mainly the costumes that came from the San Lázaro Archipelago. This relationship was broken and forgotten in 1821 when Mexico achieved its independence and Spain reclaimed its control over the Philippines.

Bernal was part of the diplomatic Embassy of Mexico in the Philippines during the 1960s. This undertaking enabled him to reconsider the historical connections of the two countries. In his four years of working in Asia, he was able to get in touch with various intellectuals living in Manila. It was not clear if he was able to meet the Filipino writer Antonio M. Abad. Howver, it is the goal of this paper to demonstrate how the literary discourses of both writers used similar strategies. Grounded on a close reading exercise, it is possible to conclude that two Bernal's short stories could be based on the novel El Campeón by Abad.

"De gallos y gallinas" and "Un día patrio" are the titles of the two short stories by Bernal that I analyze in this article. In "De gallos y gallinas", the author represents the same scenario used by Abad in his novel, El Campeón. Bernal defends the coop as the place where the Philippines can recognize themselves as Philippines. Social classes, good people, bad people do not exist in the coop. There, everyone is just a Filipino, and Bernal presented that idea in the same way that Abad did. In "Un día patrio", the Mexican writer uses another topic that greatly interests Abad: the historic national confrontation about the existence of a unique Philippine identity. The plot of the short story takes place during the Philippine's Independence Day. It tells the contradictions among the members of a family who live in Intramuros after World War II, and because of the destruction of their country, they have doubts if it is appropriate to celebrate or not. However, those who want to celebrate Independence Day and those who do not want to do it made an agreement: the coop is a place that serves as a great equalizing element. Thanks to this stories and others not mentioned here, it is possible to affirm that in Bernal's poetic, the coop is the place where Latin America and the Philippines embrace their historic bond. 
The paper is divided into two sections. The first one shows a literary biography of Bernal, with special focus on his life before he ventured to Asia. The second part of the article presents the intellectual influence that Bernal found in the Philippines and how it enabled him to write his masterpiece, El gran océano.

\section{Keywords}

Biography, El Campeon, El Gran Océano, Mexico, Rafael Bernal 


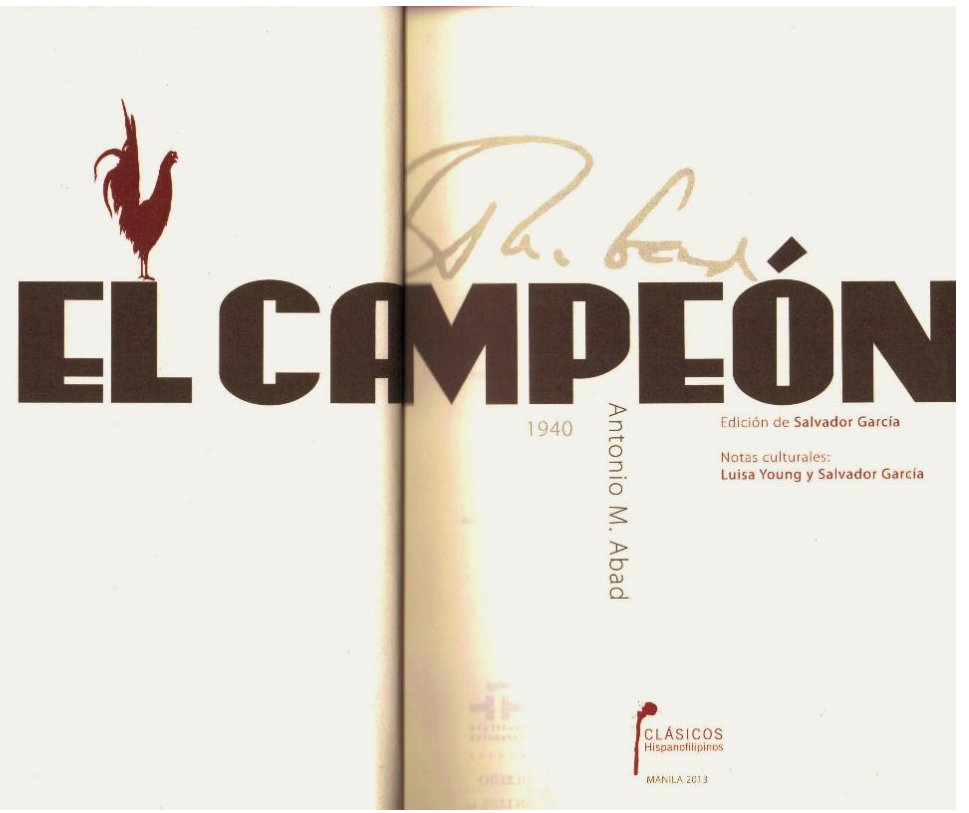

Fig. 1. Edición moderna de El Campeón, en Clásicos Hispanofilipinos (2013) 


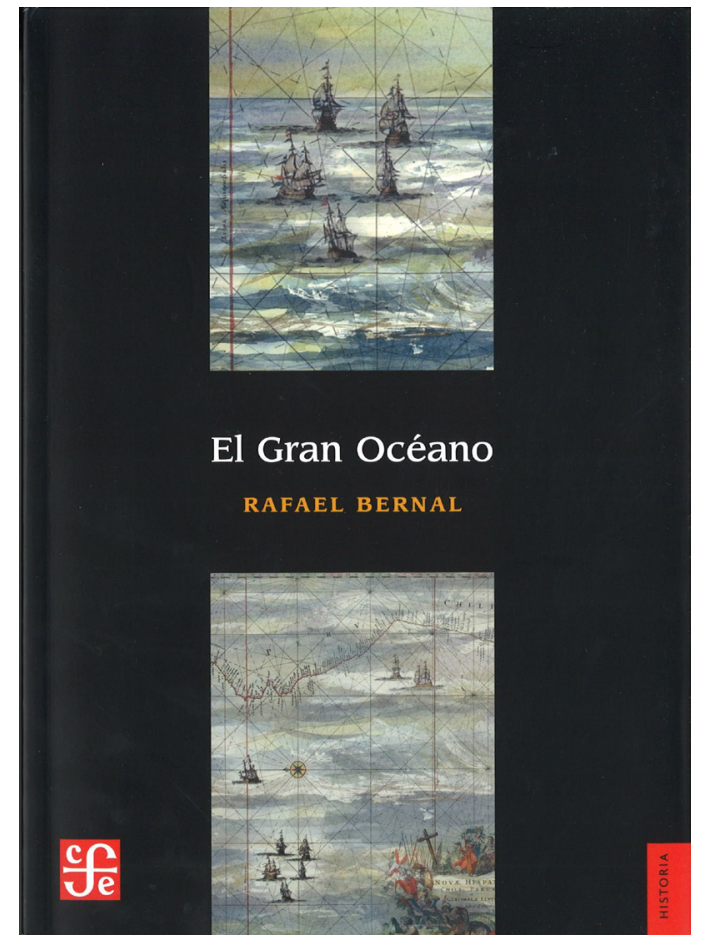

Fig. 2. El Gran Océano (1992), por Rafael Bernal

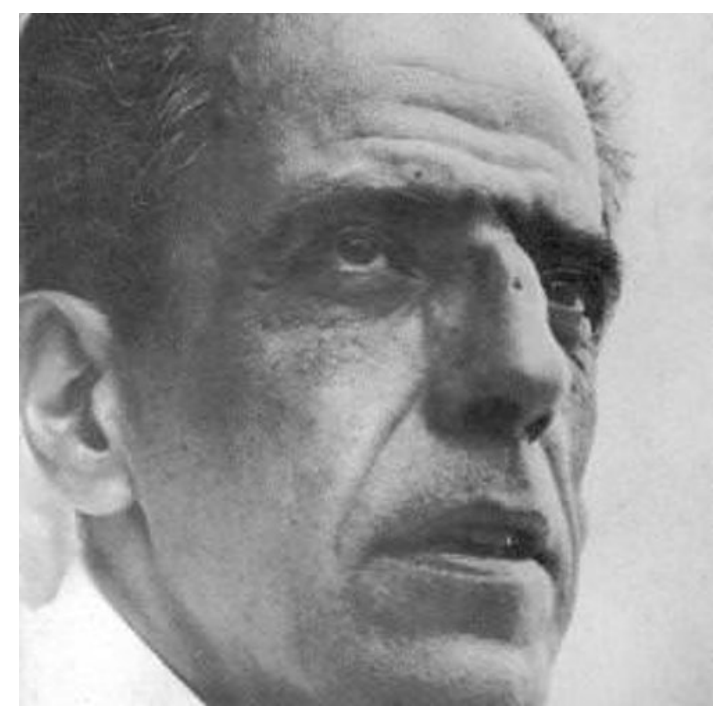

Fig. 3. Rafael Bernal, escritor mexicano 
El complot mongol es la pieza clave de la literatura negra en México. Pese a la tradición del género en el país que, sustentada en diversos proyectos, narraciones y revistas, puede rastrearse décadas atrás de la publicación de la novela en 1969, la historia escrita por Rafael Bernal estableció los mecanismos para apropiarse, desde la cultura nacional, de los paradigmas que exigen los relatos de crimen. A la necesidad de resolver un misterio, la figura del antihéroe convertido en investigador y los avatares del o los protagonistas en su búsqueda por la verdad, el mexicano agregó la atmósfera decadente de un régimen político putrefacto (en ese momento el del Partido Revolucionario Institucional, emanado de la Revolución de 1910), el acoso imperialista de Estados Unidos y Rusia hacia Latinoamérica, y el desencanto por una existencia en la que ni resolviendo el caso, ni con la misericordia de Dios, puede alcanzarse la paz entre los hombres. Como muestra de lo anterior pueden citarse las reflexiones de Filiberto García, viejo revolucionario protagonista de la obra: "La Revolución no se ha convertido en nada. La Revolución se ha acabado y ahora no hay más que pinches leyes. Y así, por todos lados, nos andamos haciendo pendejos. Todos, de una manera o de otra. Con mucho primor, como dicen los corridos" (67). El complot mongol es una pieza magistral en la que, a la par de seductora narración, el autor experimenta con las voces narrativas, crea atmósferas únicas y presenta a la Ciudad de México como ese Aleph donde el universo entero puede, no sólo experimentarse, sino también sufrirse hasta el hartazgo.

Desde su aparición la novela sedujo a los más jóvenes y, pese a su valía, se volvió una obra de culto. El grupo selecto de lectores que conocían su existencia no comprendían el poco impacto masivo de tan extraordinaria obra. Sólo a partir de las últimas décadas el nombre de Rafael Bernal ha empezado a dimensionarse en todos los aspectos que exploró como creador. Poeta, ensayista, investigador, narrador, guionista de Hollywood, dramaturgo, político y explorador, en su discurso literario muestra las pasiones que marcaron su vida. Una de las principales fue la investigación de los acontecimientos que pusieron en "el corazón del mundo" a México, entendido por el autor como esa nación gestada a partir de la mezcla de indios, españoles y africanos, y cuyo eje de acción se da por medio de la exploración del Océano Pacífico, con 
Filipinas como núcleo de contacto con Asia. Aún con la popularidad que ha logrado El Complot Mongol, las pesquisas de Bernal sobre los mexicanos y sus nexos con el Mundo carecen del eco del que tendrían que gozar tanto en el plano nacional, como en el internacional.

Dos aspectos fueron provocando el silenciamiento de una escritura tan importante como la de Rafael Bernal. El primero de ellos fue su deceso, ocurrido el 17 de septiembre de 1972 en Berna, Suiza. Luego de una carrea diplomática que lo había llevado, en la segunda mitad del siglo XX, a Honduras, Filipinas, Japón y Perú, en Europa encontró la muerte. Tantos años alejado de los circuitos literarios en México, hicieron que sus libros, publicados antes de su partida, fueran excluídos poco a poco de la tradición. La segunda de las razones, y acaso la más importante para su omisión del canon mexicano, fue su inclinación política hacia el conservadurismo. Cronológicamente Bernal es hijo de la Revolución Mexicana y de la Primera Guerra Mundial. La generación de autores que vio la luz alrededor de 1914 en el país cuenta con nombres tan sobresalientes como Octavio Paz, José Revueltas, Efraín Huertas, Rafael Solana, José Luis Martínez y Alberto Quintero Álvarez. En los años treinta, cuando empiezan su adolescencia y juventud, las figuras más sobresalientes de la promoción se inclinan por las luchas de izquierda. Varios de ellos ingresarán en el Partido Comunista Mexicano, apoyarán al gobierno del General Lázaro Cárdenas en la ayuda y en el refugio a los republicanos españoles que huían tras la Guerra Civil, y fundarán proyectos donde muestran claramente su ideología. Muestras de ellos son las revistas Barandal, Cuadernos del Valle de México y Taller. En la llamada "década roja", que se extenderá hasta la finalización de la Segunda Guerra Mundial, cuando naciones capitalistas y comunistas se unen para combatir al amenazante nazismo, Bernal elige el otro lado de la trinchera.

Luego de su aventura a los 18 años en la selva del sureste mexicano, donde buscaba hacer fortuna, y de haber estudiado cinematografía en París e incursionar en el mundo creativo hollywoodense, en los años cuarenta el escritor se unió al Partido Fuerza Popular, brazo político de la Unión Nacional Sinarquista (UNS). Se trataba de una agrupación sociopolítica de carácter católica, conservadora y opositora al régimen, nacida oficialmente el 
23 de mayo de 1937 en la emblemática calle de Libertad, en ciudad de León, Guanajuato. En un principio, el organismo fue acusado de recibir financiamiento y entrenamiento de espías nazis en México, y de estar ligado a las huestes cristeras que, una década antes, habían emprendido una sangrienta guerra en contra el Estado Mexicano. Para cuando el escritor entra a sus filas, la UNS no dejaba de subrayar su carácter pacífico y de apoyo a las clases más desfavorecidas del país, como campesinos y obreros. Sin embargo, sus acciones, más simbólicas que combativas, no dejaban de causar molestia entre el gobierno.

Eso mismo sucedió en la Décima Junta Anual de líderes de la Unión, llevada a cabo en diciembre de 1948 en la Ciudad de México. La reunión terminó en la Alameda Central frente a la estatua de Benito Juárez. Luego de los discursos en contra del Benemérito de las Américas Bernal, uno de los dirigentes del mitin, azuzó a los asistentes a encapuchar la estatua de Juárez, "el representante por excelencia del laicismo mexicano y, por ende, el canalla más grande de la historia de México para los sinarquistas, [...] provocando la ira de las autoridades" (Hernández 302). A consecuencia de estos actos, varios jefes, entre ellos el escritor, fueron encarcelados. Además, el Congreso Mexicano proclamó el natalicio de Juárez como fiesta nacional y, el 28 de enero de 1949, la Secretaría de Gobierno, a cargo de Adolfo Ruiz Cortines, canceló el registro de Fuerza Popular quedando fuera de las elecciones de julio de 1949.

Las experiencias en sus luchas sociales, las plasmó en los libros Federico Reyes el cristero (1941), Improperio a Nueva York y otros poemas (1943), Memorias de Santiago Oxtotilpan (1945), Su nombre era muerte (1947) y El fin de la esperanza (1948). Para la década de los cincuenta, el escritor abandonó sus aspiraciones políticas. Consideró corrompida la UNS por haber abandonado la lucha a favor de los más pobres del país. Se volcó entonces hacia la literatura y publicó Gente de mar (1950), un delicioso volumen de ensayos donde da cuenta sobre diversos personajes, desde piratas hasta pilotos del Galeón de Acapulco, que le habían seducido desde sus primeros años como lector. La letra es destino. Bernal pudo comprobarlo cuando ingresó al Servicio Diplomático Mexicano, donde le fue encomendada la secretaría de la 
Embajada Nacional en Manila. En el año de 1961 emprendió el viaje rumbo al Pacífico, al igual que lo hicieran los personajes de los que tanto había escrito. En Filipinas encontrará almas siamesas en la literatura, un mundo ya imaginado y un ambiente propicio para gestar una narrativa sobre el archipiélago apenas conocida. Pero sobre todo hallará el afluente para nutrir su gran obra maestra, imprescindible en cualquier estudio sobre la región: El gran océano.

En la literatura de Bernal no existe otra propuesta de tal envergadura como la historia del Pacífico que le llevó varios años de su vida. El libro se inscribe en el mismo canon de la literatura mexicana que, durante el siglo XX, tiene ejemplos tan sobresalientes como Sor Juana Inés de la Cruz o las trampas de la fe, de Octavio Paz (1983); Pasado inmediato y Última Tule, de Alfonso Reyes (1997); La Raza Cósmica, de José Vasconcelos (2002); Nueva grandeza mexicana, bajo la firma de Salvador Novo (1946), y La invención de América, de Edmundo O'Gorman (2008). Todos y cada uno de ellos se inscriben en los ensayos postrevolucionarios que buscaron retratar un momento histórico del país, pero al mismo comprender la actuación de México en el plano global. Ya sea enfocados en un personaje, ya sea buscando plasmar una época o diseccionar una ideología, los textos mencionados forman parte de una nómina de altísimo nivel intelectual cuyas huellas han fundado corrientes de pensamiento nacionales. De este calibre es el aporte que hace Bernal con su trabajo sobre el océano que une a América con Asia.

\section{Navegando desde Acapulco hasta Manila}

Nueva España, 1565: el deseo de establecer una ruta más rápida hacia Oriente, sin tener que bordear la costa africana, como pretendía originalmente Cristóbal Colón, aún no cesa entre los europeos en América. El comercio y la dominación de nuevas tierras sigue siendo el sueño más preciado tras la caída del Imperio Mexica. La aventura rumbo al Gran Océano implicaría no sólo la reafirmación del poderío marítimo del Imperio Español, sino también la definición de la nueva patria mexicana que había empezado a componer su fisonomía con la llegada de los españoles al continente.

Debido al conocimiento y la experiencia de Juan Pablo de Carrión respecto al llamado "tornaviaje" - la corriente transpacífico que hacía posible 
el regreso de Asia rumbo a América- y su apoyo en la primera expedición de la que finalmente fue excluido por Andrés de Urdaneta, cosmógrafo, marino y religioso agustino encargado del proyecto, los aventureros lograron la conquista del hasta entonces conocido como Archipiélago de San Lázaro (Gil, Hidalgo Nuchera). Las crónicas del momento narran la hazaña: "Ello es cosa grande y de mucha importancia: y los de México están muy ufanos con su descubrimiento, que tienen entendido que ellos serán el corazón del mundo" (Bernal 45). En los textos se habla de los "vasallos del rey de Castilla", pero también de "los de México", definición para el conglomerado de novohispanos, criollos y españoles que conformaron la primera exploración exitosa en suelos orientales, y a la que se sumarían indios tlaxcaltecas en las siguientes embarcaciones, tal y como lo habían hecho en otras regiones de América.

Es decir, "los de México", como se clasificaron en la época, ya eran lo que Bernal señalaba como el origen del mestizaje en el país. Se trataba de individuos que transportaban ideas y formas de vida. Es necesario destacar que, para el escritor, más que una cuestión basada en la biología o en territorio, cuando habla de "mexicanos" se refiere a la nueva cultura, con sus discursos, su imaginario, su gastronomía, su manera de posicionarse el Mundo, que había nacido al otro día de la caída de Tenochtitlán en 1521. Los de México eran españoles que habían adoptado costumbres indígenas, criollos que asimilaban sus tradiciones mestizas, indios que hablaban castellano y practicaban el catolicismo, africanos que comían tortillas como dieta diaria. Desde esta perspectiva de intercambio de ideas, conocimientos, acciones cotidianas, es como Bernal va forjando su concepto siempre dinámico de patria que, al darse el intercambio con Asia, vuelve a nutrirse de nuevas perspectivas en todos los niveles de su accionar. Esos mexicanos habían zarpado el 21 de noviembre de 1564 del puerto de Navidad o de Juan Griego, como era conocido en ese entonces, y lograron la ocupación de territorios asiáticos del Pacífico Sur. La proeza estableció la primera ruta de comercio mundial de la historia al unir tres continentes durante 250 años: Asia, América y Europa.

El comandante de la flota se llamaba Miguel López de Legazpi y Gorrochátegui, español que había echado raíces en México por más de 30 
años. En la tropa destacó su nieto, Juan de Salcedo, novohispano de nacimiento que a la postre sería el fundador de la amurallada ciudad de Manila. De su exploración se instauró la Capitanía General de las Filipinas. Su administración quedó a cargo del Virreinato de la Nueva España con capital en la Ciudad de México. El Galeón de Acapulco o Galeón de Manila o Nao de China se hacía a la mar, cargado de plata mexicana y oro peruano. En Filipinas comercializaba con los pueblos malayos, chinos, japoneses y cualquiera de la región que quisiera hacer negocios con los llegados del otro lado del mundo. Los productos traídos a América eran múltiples: especias, marfil, porcelana, seda, laca, muebles, canela, algodón, textiles, arte sacro e incluso diamantes. La mayoría se quedaba en México. Otra parte se enviaba a Perú o Veracruz, para ser embarcado hacia España, vía La Habana. El intercambio provocó el sincretismo cultural entre América y Asia que Bernal (2012) describe de esta manera:

Teóricamente toda la mercancía del galeón debía pasar a España, pues estaba prohibido el comercio entre una colonia u otra, pero en la práctica la mayor parte de la mercancía quedaba en la Nueva España y una parte considerable de ella pasaba de contrabando a Perú, de donde llegaban cada año uno o dos barcos a Acapulco a esperar la feria. Así, el impacto económico y social de China y Filipinas, se hace mucho más notable en México que en el resto del imperio. Muchas de las costumbres mexicanas, muchos de los actuales productos, celebraciones, objetos de lujo, tienen su origen en el galeón, como las peleas de gallo con navaja, importada de Filipinas, así como los extraordinarios mangos de Manila que conservan ese nombre en México. El papel de China o papel de seda para hacer picaduras y adornos conserva también, en su nombre mexicano, la huella de su origen. Los fuegos artificiales, llamados castillos en México, fueron importados de China y se sabe que el virrey Enríquez solicitó se le enviaran dos expertos pirotécnicos para que los indios aprendieran a hacerlos. En las fiestas que se celebraron en la Ciudad de México desde principios del siglo XVII encontramos constantemente la mención de terciopelos y sedas de China como parte del vestuario de comparsas y de los caballeros [...]. Los alfareros de la ciudad de Puebla, enseñados a fabricar la "talavera" con sus hábiles manos antiguas, se dejaron llevar por la influencia de los dibujos Ming, también en azul y blanco, y empezaron a hacer tibores con pagodas y dragones; asimismo, los talladores peruanos de piedras de Huamanga empezaron a hacer leones imperiales de Pekín. Así, las costumbres criollas americanas, sobre todo en México, 
se vieron modificadas por el comercio de Oriente en forma importante y gran parte de ese lujo mexicano que tanto asombra al barón de Humboltdt a principios del siglo XIX era una herencia del comercio de la Nao de China (240-241).

Al centro -en el corazón del mundo, como lo establecen los documentos citados por el escritor- de esa convulsión comercial se encontraba México y su riqueza, pero además una cultura que no era ni española ni indígena ni negra, sino una mezcla de las tres y que, como se lee, empezó a nutrirse de costumbres asiáticas. Ese fue el momento en que nació el mexicano moderno como protagonista en el concierto de la historia. Las referencias a esa nueva cultura, gestada de la unión entre españoles y nativos, pueden leerse en las correspondencias oficiales que se dirigían del Virreinato de la Nueva España a La Corona: "Copia de una carta venida de Sevilla a Miguel Salvador de Valencia. La cual narra el venturoso descubrimiento que los Mexicanos han hecho, navegando con la armada que su Majestad mandó hacer en México. Con otras cosas maravillosas, y de gran provecho para toda la Cristiandad: son dignas de ser vistas y leídas” (Bernal 45).

Los documentos llegan a nosotros por medio de las obras que Rafael Bernal escribió durante su estancia en Oriente. México en Filipinas. Estudio de una transculturación es el título en el que recupera sus primeras visiones en el Archipiélago. Su experiencia en Manila duró cuatro años: de 1961 a 1965. Lo que descubrió en su estadía al otro lado del Pacífico no fue un pueblo ajeno, sino que se reencontró con su país. En las sonrisas de los filipinos, en su manera de enfrentar la derrota o las catástrofes, en su organización caótica de la vida donde subyace un sentido religioso con ecos aún más hondos que el evangelio cristiano, pero que en el sincretismo con los ritos católicos hallan su mejor expresión popular, Bernal fue reconociendo una tradición que inevitablemente compartía el alma con los de tierra americana. Fue tanto su asombro que lo volcó en conocimiento. Sobre territorio asiático escribió el artículo "The Chinese Colony in the Philippines, 1570-1770", incluido en el volumen The chinese in Philippines (1966), y el prólogo a Philippine's History (1967). De la misma manera Filipinas nutrió su ficción. En Manila escribió Tierra de gracia (1963), ambientada en Venezuela, y En diferentes mundos 
(1967), cuyos cuentos "El ciclista tuerto" y "El mexicano" tienen como espacio narrativo la capital filipina. Por último, en tierras asiáticas dio a luz a la que él consideraba su máxima obra, más que cualquiera de sus novelas, titulada El gran océano.

La obra de Bernal se compara con El Mediterráneo y el mundo mediterráneo en la época de Felipe II, de Fernand Braudel, como bien lo señala Alfonso de María y Campos Castelló, en "Prólogo” a la edición de 2012, el volumen es una deliciosa de pieza que navega sin mancha y sin peros por los recursos literarios e históricos. Bernal expone su erudición de una geografía, el Pacífico, donde se dieron algunos de los pasajes más importantes de la humanidad, sin distinción entre clasificaciones como Oriente y Occidente. Es en El gran océano, editado como una obra póstuma por primera vez por el Banco de México en 1992, donde el autor se regodea en uno de los temas que más estudió en su vida. En el volumen ofrece una cronología desde el principio de los tiempos hasta el siglo XIX de ese fragmento del mundo en el que los sueños de riqueza y fama nacieron junto a las aventuras de piratas, batallas navales y gestas poco conocidas o acontecimientos perversos.

Sus más de 500 páginas en formato medio oficio muestran no sólo el compendio de gran cantidad de datos, tan ricos como extraordinarios, de una región donde múltiples culturas, imperios y personajes se imbricaron, sino también la reflexión de toda una vida pensando en el mar, como fue la de Bernal. Para el mexicano había dos clases de pueblos: los que veían en el mar una barrera y aquellos que pudieron conceptualizarlo como una vía más rápida de comunicación. La historia demuestra cómo la segunda clase de pueblos son los que lograron las grandes hazañas, pero a diferencia de los discursos oficiales, el mexicano creía que esas grandes hazañas sólo pudieron lograrse a partir de los individuos que rodeaban a los nombres destacados en los registros oficiales. Hacia esos hombres volcó su visión, lo que hace de $E l$ Gran Océano una mirada múltiple de los hechos narrados, alejada de cualquier rasgo imperialista, ya sea desde Europa o Estados Unidos, como la que padece gran parte de los estudios que se han hecho al respecto. En su momento, José Luis Martínez señaló: 
pero antes que limitarse a reunir las experiencias de los grandes viajeros, Bernal se propuso estudiar el pensamiento, siempre cambiante, de los hombres que llevaron a cabo esas empresas, según las diferentes maneras de pensar de los pueblos expansionistas, que modificaron las formas de contacto con los pueblos (1-2).

El matiz sobrio del libro está hermanado al carácter sobrio del autor. En su ficha del expediente del Servicio Exterior, el diplomático Rafael Bernal es descrito como un hombre "casado, de 1.89 de estatura, tez morena, pelo negro, frente grande, cejas espesas y juntas, ojos castaños, nariz convexa y boca mediana” (De María 17). Al llegar a Filipinas trabajó a cargo del embajador Muñoz Zapata y debido a su extraordinaria labor el escritor es ascendido a primer secretario. De 1961 a 1965 desempeña sus labores diplomáticas en Manila. Durante este lapso el mexicano fue responsable de los trabajos culturales de la visita oficial del presidente Adolfo López Mateos al Archipiélago, como parte de los festejos del 400 aniversario del viaje de Legazpi. Gracias a las gestiones de Bernal visitaron el país otros intelectuales mexicanos, como Jaime Torres Bodet, Miguel León-Portilla, Ignacio Chávez y Luis Villoro, quienes ofrecieron charlas, conferencias y talleres. De la misma manera estableció, junto con académicos de la Universidad de Santo Tomás, una corriente intelectual transpacífica en la que al parecer participaron diversos pensadores de ambos continentes. En todos los sentidos, el trabajo de Bernal en Filipinas fue destacado:

La gira de López Mateos fue un éxito en lo diplomático; su propósito más ambicioso era la búsqueda de una defensa conjunta de los precios de las materias primas producidas "por los países en desarrollo, y abrir nuevos mercados especialmente para los manufactureros mexicanos, y las fuentes de diversificación de la inversión extranjera”. El recorrido que tuvo lugar en el otoño de 1962 incluyó la India, Filipinas, Indonesia y Japón; llevó también un mensaje de paz y la propuesta de una política para el control del armamentismo y los ensayos nucleares (De María 38).

Es interesante pensar en el panorama que encontró Rafael Bernal a su llegada al Archipiélago en los años sesenta. El español moría en Filipinas 
y había un puñado de intelectuales, entre los que destacaba Antonio M. Abad, que se negaban a la catástrofe que les arrancaría el espíritu hispánico. Durante la primera mitad del siglo XX, cuando se llevan a cabo las políticas más férreas para imponer el inglés como idioma oficial en el país, diversos escritores desarrollaron obras fundamentales de la literatura en español de Oriente, dando a luz a lo que se denomina la Época de Oro de las Letras Hispanofilipinas. Una gran variedad de tonos y textos se agrupan desde 1896 a 1967. Poesía clásica, relatos de tradición oral, ensayo literario, novelas río, de crecimiento e históricas, son apenas algunas coordenadas por las que deambula la literatura en castellano en Las Filipinas (García, El campeón).

Manifestaciones tan interesantes como el Modernismo, con Latinoamérica como núcleo de gestación, encuentran eco en el Archipiélago. El máximo representante del movimiento en Filipinas fue Jesús Balmori (1886-1945), quien a la edad de 17 años publicó un libro revolucionario en la lírica filipina: Liras malayas (1904). A la par del modernismo, otra de las líneas donde se utilizó a la literatura como herramienta de cohesión cultural ante la embestida del inglés fue la narrativa. Unas de las novelas más importantes de las letras hispanofilipinas es La oveja de Nathán (1929), del escritor Antonio M. Abad, la cual fue publicada por entregas a partir de 1928 en el periódico La Opinión y se hizo merecedora del Premio Zóbel. La narración hace guiños a la palabra de Galdós, Tolstoi y Dostoievski. Trata de abarcarlo todo, de exponer sin límites las características que marcaron el rumbo de la humanidad a principios del siglo XX. El refugio y paternalismo literario que haya en las figuras de estos autores no implica que Abad fuera ajeno a lo acontecido en la literatura en español de su tiempo; sin embargo, la lejanía geográfica con España y Latinoamérica le fue un impedimento para seguir puntualmente la evolución de las letras en castellano. Lo mismo sucede con otras de las obras hispanofilipinas, sobre todo en la narrativa: parecen anacrónicas, demasiado distantes a las experimentaciones literarias que se dieron a principios del siglo XX en la literaria en castellano.

Este desfase no es casual. No existe otro ejemplo en la historia del español donde el idioma esté condenado a morir. Estos literatos fueron conscientes del significado de escribir en castellano en un momento donde la oscuridad 
del mutismo les rondaba cada vez más de cerca. La literatura hispanofilipina trascendió así sus objetivos meramente estéticos a fin de situarse en un lugar privilegiado a camino entre el panfleto y el ideario político. Los escritores filipinos en castellano carecían de tiempo para detenerse y pensar sobre las diversas aristas, corrientes, discursos, que podrían explorar por medio de sus letras con el propósito de alejarse del discurso literario europeo, como sucedió durante la misma época en Latinoamérica. Sin ningún horizonte adonde su palabra pudiera trascender y con la asfixia anglosajona acrecentándose un día tras otro, la literatura fue su arma, su espíritu, finalmente su vida. A los anterior se suma el antiyanquismo de la generación que padecía la asfixia estadounidense en su propia tierra, lo que provocó que el idioma fuera igualmente un arma de resistencia.

Con el panorama que urgía acciones desde la literatura, Rafael Bernal coincidió con Antonio M. Abad. La relación entre los escritores es desconocida hasta la fecha, pero puede comprobarse fácilmente. En el archivo del filipino se conservan documentos e invitaciones oficiales para participar en los actos culturales que llevó a cabo el presidente mexicano López Mateos en Manila. El vínculo también se demuestra con el acercamiento que Bernal hizo a los ensayos de Abad: los dos escritores compartieron inquietudes que marcaron profundamente su obra. Les preocupaba, en primer término, la recuperación del nexo, roto desde 1821, entre México y Filipinas. Bernal volcó el tema en los libros históricos mencionados líneas atrás. De su lado, en el ensayo "Méjico [sic] y Filipinas: la historia se repite”, Antonio M. Abad escribe expresiones como "en realidad Méjico fue el evangelizador de Filipinas” y “de México venían los mejores gobernantes de Filipinas”, para finalmente señalar la necesidad de que estos países rescaten el pasado que los une:

La madurez nos ha desligado de España. Mucho antes de esa separación, México buscó y encontró la libertad. Era la más compatible con su propia madurez. Mientras la buscaba cuidó sólo de sí misma, olvidando por un momento que tenía en el Pacífico una hermana menor a quien en la infancia rodeó de halagos. De su lento crecimiento fue testigo; y ahora, en la comodidad de su propia casa, Méjico recuerda 'aquellos tiempos'. La mayor y la 
menor son libres. ¿No es hora de que, juntas otra vez, se cuenten sus alegrías y sus tristezas? (Archivo Abad, cajas 70 y 86).

Las afirmaciones de Abad estaban basadas en la historia, es decir, en ese pasado que tenían que recorrer los filipinos para proyectar su futuro. En ese pasado estaba como foco primordial México. Los dos países guardaban alma indígena y, al mismo tiempo, eran pueblos con una herencia hispánica, tanto en la religión como en el idioma, que los identificaba. En el ámbito cultural y comercial, México y Filipinas habían estado ligados por casi tres siglos a través del Galeón de Acapulco. Sin embargo, hasta el día de hoy tanto en México, como en Filipinas (posiblemente más en América) la relación entre estos dos países suena exótico, raro, fantástico, ilusorio, por decir lo menos. La historia mexicana, como lo decía Octavio Paz, está construida a partir de la negación. Una de las zonas oscuras de nuestro pasado es El Virreinato, un lapso que se percibe anquilosado, donde lo más destacado es que las desigualdades y las ideas de la Ilustración provocaron el movimiento independentista de 1810. Pero justo de ese momento es del que hablaba Abad en sus ensayos, cuando el Pacífico hermanó a los dos pueblos.

El segundo de los problemas que ambos escritores abordaron fue la identidad de los filipinos lacerada por el alejamiento con América y España debido a la pérdida del idioma, y asimismo avivada por las invasiones norteamericanas, a finales del siglo XIX, y japonesa durante la Segunda Guerra Mundial. En sus textos Abad realizó una férrea defensa del español en el Archipiélago. Se valió del lenguaje para combatir, denunciar, exigir. Negó el silencio, pensaba sobre la hoja en blanco, escribió en voz alta. Con el castellano como base pretendió hallar una identidad filipina propia, lejos de las amenazas extranjeras y con guiños al pasado mexicano en Oriente.

El porvenir del Archipiélago, ese momento que sólo sería palpable cuando sus coterráneos se hicieran conscientes del horizonte, se tenía que empezar a labrar en el día a día sin olvidar su pasado en América. En su texto titulado “¿Cuál es nuestro destino?”, expresa:

Y esto, que se llama inmodestamente 'escuelas del pensamiento filipino moderno', no es más que síntoma de desorientación. Ha habido siempre 
en la historia de los pueblos y de las razas este momento pasajero de vacilación. Atravesamos ahora por él. Pero de pronto en los que vacilan significa incomprensión del destino histórico de nuestro pueblo. Quien es incapaz de comprenderlo no debe aspirar a dirigirlo (220).

Comprensión del "destino histórico" es lo que exigía a los gobernantes de su país, pero también a los propios filipinos. Y esa comprensión iba de la mano del idioma. Si Filipinas había perdido el rumbo, como lo señalaría en sus ensayos posteriores, sólo por medio del castellano podría recuperar ese pasado donde reconocería su origen. Para Abad el español era la palabra llave. El castellano significaba herramienta, misterio y comunión. Herramienta para descifrar el mundo, misterio del cristianismo que llegó en español al Archipiélago y comunión con los pueblos hispanohablantes, desde España hasta Argentina.

Esas obsesiones también las expusieron en sus obras de ficción. Abad escribió El Campeón. La novela se basa en la pelea de gallos para ofrecer un atisbo de la vida filipina. En el texto no se olvida de su herencia mexicana:

Aludiendo a sus experiencias en Manila, Pulá le decía que [el gallo] el mejicano era notable no sólo por su habilidad, como por su heroica valentía. Un adversario superior puede motear de heridas su cuerpo pero jamás lo vería echarse a correr: preferirá morir con el pico clavado en el suelo a dar la espalda al rival (184).

Abad no trata sólo de defender esta práctica como un deporte enraizado en lo más profundo del espíritu filipino, sino que las peleas de gallos le ofrecieron el espacio y la acción idóneos para retratar su entorno y plantear las preguntas necesarias sobre el sentir del Archipiélago. La génesis de novela puede rastrearse en los recuerdos más lejanos del autor:

Hace años, allá en mi mocedad, presencié esta escena:

Sobre la tibia humedad del polvo callejero, suavemente apisonado por la llovizna de la noche anterior, una media docena de hombres se afanaban en el adiestramiento [de] unos doce o quince gallos de pelea. Todos estaban en cuclillas y, mientras, comentaban en voz alta las habilidades de cada 
gallináceo gladiador, que sujeto sobre el suelo por la pata derecha con fuerte cuerda de abacá terminada en clavo de hueso hincado en la tierra, lanzaba su clarín de reto bajo el ocioso silencio pueblerino.

Dos de los amaestradores careaban entre sí, sujetándolos por la cola, dos gallos de pelea. Dábanles fuertes palmadas por las cobijas, obligándolos a inclinarse ora a la derecha, ora a la izquierda, acostumbrándoles así a resistir las embestidas del enemigo en los choques de cuerpo a cuerpo. De pronto, entre los contertulios surgió una disputa. Las voces, reposadas al principio, subieron gradualmente de diapasón. Uno de ellos, más fuerte y, como casi siempre, más falto de razones también, se alzó de improviso y dio un fuerte empujón a su adversario que, dada su posición, rodó por el suelo dando dos o tres volteretas. De la voltereta se levantó el ultrajado, los ojos llameantes, el semblante contraído y reflejando una decisión homicida: la mano derecha blandía un cuchillo...

A pesar de la violencia que puede brotar durante el evento con resultados mortales, la gallera filipina es un centro de aprendizaje y convivencia. Es una de las formas más destacadas que tienen los pobres de crecer en comunidad. Para entenderse como un todo sirve la comunión que se da en la victoria, pero sobre todo en la derrota. En el ruedo se demuestra el honor, la caballerosidad, el ingenio. Se grita y se calla, se vive al máximo porque se ve de cerca a la muerte. Es ahí donde el filipino alcanza a mirarse a los ojos y reconocerse en el otro. Sólo en el ruedo, se explica en El campeón, se vuelve al origen del archipiélago. La euforia le sirve al filipino como catalizador. El pueblo es uno porque es muchos: realidades diversas, sueños multiplicados en un espejo, la sonrisa del delirio, la miseria frente al cielo, matices de necesidad y bonanza hilvanados en dos o tres minutos según dure la pelea. Cuando la sangre llega, se rompe el encanto: el tiempo deja de ser eterno.

El mismo espacio, la gallera y su simbología, es abordado por Rafael Bernal en dos narraciones que permanecieron inéditas hasta 2006. La primera de ellas es "De gallos y gallinas", donde se narra la discusión entre dos hermanos filipinos de origen campesino sobre el género sexual de uno de sus gallos. Lo llevan a pelear para salir de dudas, como si el ruedo fuera el lugar privilegiado para demostrar la hombría. El mexicano conoce el código de la gallera: la palabra como sustento del mundo, la religiosidad permeada 
por la sangre, el historial de los gallos mexicanos (él le llama tejanos), la violencia desbordante. Pero Bernal incluye otro elemento al ruedo: el deseo amoroso:

Mi hermano no me quiso oír. Se formalizó la pelea y le amarraron las navajas en las patas a los gallos. Dije una oración silenciosa a Santa Rita de Casia, abogada de imposibles. Soltaron los animales en el centro del palenque. El tejano empezó a escarbar la arena como si estuviera preparando la tumba de su adversario y, momentos más tarde, los dos campeones se enfrentaron. Pensé que nuestro animal se moriría de miedo, pero sucedió una cosa extraordinaria. Una expresión amorosa llenó los ojos del gallo colorado que empezó a hacer la ronda. Naturalmente esto llamó mucho la atención de la gente, sobre todo, a los que apostaron al colorado, porque saltaba a la vista que el gallo estaba profundamente enamorado de nuestro animal y que sus intenciones, por el momento, eran estrictamente amatorias. Pero antes de que alguien pudiera protestar, nuestro pájaro se lanzó contra el colorado, la golilla levantada y, de un solo salto, clavó la navaja en el pecho de su adversario.

Es así que Bernal también presenta la gallera como el lugar privilegiado de la comunión y el reconocimiento de los individuos por medio de la violencia. Característica muy filipina, característica muy mexicana, característica muy latina.

El mexicano volvió a tocar el tema de la violencia y la desalación en el cuento "Un día patrio". El texto aborda el sentimiento de orfandad del pueblo filipino representado por una pareja de habitantes de Intramuros tras la Segunda Guerra Mundial. Durante el conflicto se destruyó gran parte de Manila, debido a los bombardeos, tanto de japoneses como de norteamericanos. Es necesario recordar que la zona del cuento es el espacio al que llegaron los primeros mexicanos y donde desembarcaba el Galeón de Acapulco. La referencia es imprescindible porque Intramuros será una metáfora del pasado que fue olvidado en el Archipiélago. Un olvido que no se dio por elección del pueblo, sino que se trató del resultado de las invasiones que tanto han padecido Las Filipinas. El discurso de los personajes del cuento bordea el desencanto. Para qué celebrar la independencia del país cuando ni siquiera existe un país como tal. Son pocos los que se reconocen como 
filipinos. En el cuento los sobrevivientes de la guerra son pobres, viejos y excluidos que tienen que cuidar de niños que han quedado mutilados y huérfanos tras la guerra. La muerte y el desamparo, sembrados a partir del conflicto, minan la posibilidad de reconocerse como compatriotas. Tal vez en las peleas de gallos habrá una esperanza, se rumora en la narración del mexicano con claros ecos a la novela El campeón.

El asunto en jaque es nuevamente la identidad, un asunto que sigue vivo en los intelectuales filipinos contemporáneos, como lo subraya Fernando Nakpil Zialcita (2005):

Preoccupations with a national identity have intensified among us, educated Filipinos, since Independence in 1946. We believe that diverse people of the islands should have a common vision and a sense of pride in their heritage. At the same time we have to define our role vis-à-vis Asia, Southeast Asia, the World Powers, and other nations. Moreover, we are obligated to articulate our uniqueness when planning tourism campaigns, attracting investors, selling finished products on the world market, or even when just entertaining foreign visitors (5-6).

La respuesta a esta cuestión de la identidad - tan actual como se ve- que ofrece Bernal en su cuento es la misma que ya había ensayado Abad: los filipinos tienen que volver los ojos a su pasado mexicano y latinoamericano y español, con el castellano como piedra de toque, para reencontrarse. Sólo hasta que logren realizar ese viaje de regreso a la semilla, este "tornaviaje", podrán saber sus necesidades, exigencias y contrariedades, pero también podrán labrar su futuro. Las mismas observaciones para los filipinos las proponía Bernal para los mexicanos. Dotar de una mirada crítica al pueblo para aplicar auditoría a su propia historia. Sólo conociendo el pasado podremos hacer factible un futuro. Un futuro, en el que tal vez mexicanos y filipinos, filipinos y mexicanos, se reconozcan como hermanos, tal y como lo escribieron tanto Antonio M. Abad como Rafael Bernal. 


\section{Notes}

1. Bernal 1969. Desde hace décadas la novela se ha considerado canónica y se establece la obra fundacional de la literatura negra en México.

2. Para abundar sobre la historia de la generación y sus proyectos editoriales, ver mi investigación (2016): La promoción de la revista Taller, entre la tradición mexicana y el llamado del mundo.

3. Respecto al momento histórico que enmarca a la generación Eric Hobsbawn escribe: "Sólo la alianza -insólita y temporal- del capitalismo liberal y el comunismo para hacer frente a ese desafío permitió salvar la democracia, pues la victoria sobre la Alemania de Hitler fue esencialmente obra (no podría haber sido de otro modo) del ejército rojo. Desde una multiplicidad de puntos de vista, este periodo de alianza entre el capitalismo y el comunismo contra el fascismo -fundamentalmente las décadas de 1930 y 1940- es el momento decisivo de la historia del siglo XX. En muchos sentidos es un proceso paradójico, pues durante la mayor parte del siglo - excepto en el breve periodo de antifascismolas relaciones entre el capitalismo y el comunismo se caracterizaron por su antagonismo irreconciliable” (2014, p. 17).

4. Para abundar sobre la presencia alemana en México es imprescindible la investigación de Cedillo 2010.

5. Sobre la Literatura Sinarquista, consultar mi investigación (2012): Voto de silencio: un acercamiento a la literatura Sinarquista.

6. Sobre las alianzas y posteriores colaboraciones de españoles e indios tlaxcaltecas para la expansión de la conquista en suelo americano, se pueden consultar Ramos 2015.

7. Actualmente las construcciones de históricas de Intramuros funcionan como campo de Golf, gracias a la visión pragmática de los estadounidenses. La zona en la que desembarcaba El Galeón es el moderno Barrio Chino. Agradezco al Dr. Fernando Nakpil Zialcita por la invitación que me hizo para conocer la zona, donde me explicó la visión del pueblo filipino cuya historia se forja a partir de los abusos imperialistas. 


\section{Bibliografía}

Abad, Antonio M. El campeón. Instituto Cervantes de Manila, 2012.

De la hora transeúnte, Concurso Literario de la Mancomunidad Filipina, 1940.

Balmori, Jesús 1904. Liras malayas, Tip. Lit. "Germania”, 1904.

Bernal, Rafael 2012. El gran océano. México, 2012.

.Doce narraciones inéditas. México, 2006.

.El complot mongol. México, 1969.

."Prólogo", en Philippines History, Solidaridad Publishing House. 1967.

.En diferentes mundos. México, 1967.

."The Chinese Colony in the Philippines, 1570-1770", en The Chinese in

the Philippines, 1570-1770. Edited by Albert Félix Jr., Solidaridad Publishing

House. 1966.

.1965. México en Filipinas. Estudio de una transculturación, México, 1965.

Tierra de gracia. México, 1963.

. Gente de mar. Relatos de piratas. México, 1950.

Su nombre era muerte. México, 1947.

El fin de la esperanza, Editorial Calpulli, 1948.

. Memorias de Santiago Oxtotilpan, Editorial Polis, 1945.

Improperio a Nueva York y otros poemas, Ediciones Quetzal, 1943.

Cedillo, Juan Alberto. Los nazis en México, Random House Mondadori, 2010.

De María y Campos Castelló, Alfonso. "Prólogo”, en Rafael Bernal, El gran océano, FCE, México, 2012.

."Por selva, milpa y mar: la literatura y la diplomacia extraordinaria

de Rafael Bernal 1915-1972”, en Revista Mexicana de Política Exterior, número especial 2015, pp. 7-78.

García Rodríguez, Salvador. La promoción de la revista Taller, entre la tradición mexicana y el llamado del mundo [tesis de doctorado], El Colegio de San Luis, México, 2016.

“Introducción”, en Antonio M. Abad, El campeón, Instituto Cervantes de Manila, Filipinas, 2013, pp. vii-lxiv.

. Voto de silencio: un acercamiento a la literatura Sinarquista [tesis de doctorado],

El Colegio de San Luis, México, 2012.

Gil, Juan. "El primer tornaviaje”. La Nao de China, 1565-1815. Navegación, comercio e intercambios culturales. Editado por S. Bernabeu. Universidad de Sevilla, 2013, pp. 25-64.

Hernández García de León, Héctor. Historia politica del Sinarquismo, Grupo Editorial Miguel Ángel Porrúa/Universidad Iberoamericana, México, 2004. 
Hidalgo Nuchera, Patricio. "La controversia Urdaneta versus Carrión sobre el destino de la armada de Legazpi según Luis Felipe Muro Arias”, Archivo Agustiniano, Vol. 95, no. 213, 2011, pp. 245-278.

Hobsbawn, Eric. Historia del siglo XX, Planeta, México, 2014.

Novo, Salvador. Nueva grandeza mexicana: ensayo sobre la Ciudad de México y sus alrededores, Hermes, México, 1946.

O’ Gorman, Edmundo. La invención de América, FCE, México, 2008.

Paz, Octavio. Sor Juana Inés de la Cruz o Las trampas de la fe, FCE, México, 1983.

Ramos Galicia, Yolanda, Jaime Sańchez Sańchez and Armando Díaz de la Mora. Los colonizadores tlaxcaltecas siglos XVI al XIX, Gobierno del Estado de Tlaxcala, México, 2015.

Reyes, Alfonso. Obras completas XI: Última Tule. Tentativas y orientaciones. No hay tal lugar. FCE, México, 1997.

.Obras completas: Grata compañía. Pasado inmediato. Letras de la Nueva España, FCE, México, 1997.

Vasconcelos, José. La raza cósmica, Porrúa, México, 2002.

Zialcita, Fernando Nakpil. Authentic though not exotic. Essays on Filipino Identity, Ateneo de Manila University Press, 2005. 